\title{
Information Systems and Culture
}

\author{
The World Might Be Flat, but It Is \\ Culturally Rich
}

\author{
DOI 10.1007/s12599-012-0211-y
}

\section{The Authors}

\author{
Prof. Dr. Armin Heinzl ( $₫)$ \\ University of Mannheim \\ Schloss \\ 68131 Mannheim \\ Germany \\ heinzl@uni-mannheim.de
}

Prof. Dr. Dorothy E. Leidner

Hankamer School of Business

Baylor University

P.O. Box 98005

Waco, TX 76798-8005

USA

Dorothy_Leidner@baylor.edu

Published online: 2012-04-26

This article is also available in German in print and via http://www. wirtschaftsinformatik.de: Heinzl A, Leidner DE (2012) Informationssysteme und kulturelle Einflussfaktoren. Die Welt wird kleiner, Kulturunterschiede bleiben bestehen. WIRTSCHAFTSINFORMATIK. doi:10.1007/ s11576-012-0319-1.

(C) Gabler Verlag 2012
Culture is recognized as an important factor influencing the development, deployment, and use of information systems in households and organizations as well as in the public sector. The rich concept of culture relates to the organizational, professional, and national attitudes, values, goals, and practices of the respective actors involved. Cultural intelligence is a key capability for avoiding problems and ensuring a proper fit among the constitutional elements of information systems: individuals, tasks, and information technology.

Professionals from different nations with differing cultural backgrounds and capabilities have continuously increased their level of cooperation in order to develop and deploy new systems and services. The success of global software projects, for instance, largely depends on managing the cultural diversity of the professionals involved.

In the use phase, cultural values embedded in the system deployed by a vendor may differ significantly from the cultural characteristics of the client organization. The underlying business or service processes supported span many boundaries of systems and organizations. Accordingly, the cultural diversity of the system's users and a variety of other stakeholders needs to be taken into account.

These compelling arguments motivated us to highlight the impact of culture with respect to the development, deployment, and use of information systems in Business \& Information Systems Engineering (BISE) as an international scholarly journal. We have been able to attract a substantial number of submissions and to finally select four exceptional contributions from culturally inclined scholars.

Nitin Agarwal and Rolf Wigand, University of Arkansas in Little Rock, and Merlyna Lim, Arizona State University in Tempe, demonstrate how information systems in cyber-collective social movements affect traditional roles and behaviors of individuals in societies. Their article "Raising and Rising Voices in Social Media" offers a longitudinal analysis of blogs from 17 countries over seven years in order to study the Al-Huwaider campaign for strengthening the rights of women in Saudi-Arabia. The method developed can be applied to marketing, HR, and any other settings where social phenomena can be observed.

Our second paper authored by Hanna Krasnova and Oliver Günther from the Humboldt University of Berlin and Natasha F. Veltri from the University of Tampa, USA, focuses on social networking sites. Their contribution "Self-disclosure and Privacy Calculus on Social Networking Sites: The Role of Culture" seeks to scrutinize the moderating influence of cultural dimensions on user willingness to disclose information. Using survey responses of US and German Facebook members, the authors indicate that trusting beliefs play a key role in individual self-disclosure decisions in countries with high individualism, while high uncertainty avoidance fosters an emphasis on privacy concerns.

Alexander von Stetten, Daniel Beimborn, and Tim Weitzel from the University of Bamberg have dedicated their contribution to the topic of "Analyzing and Managing the Impact of Cultural Behavior Patterns on Social Capital in Multinational IT Project Teams". Whilst conducting multiple case studies with exposure to India and the Czech Republic, von Stetten et al. argue to combine singular cultural dimensions into holistic cultural behavior patterns. This provides a better understanding of the behavior of individuals in diverse groups as well as guidelines on how to manage diverse work relationships in multinational settings.

In our fourth paper, Oliver Marschollek and Roman Beck, both from the Johann Wolfgang Goethe University in Frankfurt, look at the "Alignment of Divergent Organizational Cultures in IT Public-Private Partnerships". Using institutional logics as metatheoretical lens, their case study analyzes a public-private partnership in a German city over various months. The results reveal public- and private-side organizational culture differences and outline how the partners overcame their cultural differences by 
the development and legitimization of a partnership norm as well as the necessary partnership practices.

The four research papers are complemented with a dialogue between Alexander Mädche, University of Mannheim, and Clemens Däschle from SAP about the management of global software development practices within a global enterprise software vendor.

We would like to take the opportunity to thank all contributors and reviewers as well as Tommi Kramer for their relentless efforts and support in developing and crafting this special focus issue. We hope that this collection of papers provides a sound opportunity to demonstrate the rich facets on culture and their impact on information systems.

Finally, we wish you as the reader of BISE many stimulating insights and inspirations to further untangle the richness of culture in IS. 